\title{
Credentialing in Pharmacy Practice: Examining Pharmacist Views and Perceptions
}

\author{
Sun Lee, PharmD ${ }^{1}$; Nancy Dao, PharmD²; Micah Hata, PharmD ${ }^{3}$; Anandi V. Law, BPharm, MS, PhD, FAPhA ${ }^{3}$
}

${ }^{1}$ Fred Wilson School of Pharmacy, High Point University, High Point, NC

${ }^{2}$ Clinical Pharmacy, SCAN Health Plan, Long Beach, CA

${ }^{3}$ Pharmacy Practice and Administration, Western University of Health Sciences College of Pharmacy, Pomona, CA

\begin{abstract}
Introduction: Pharmacy practice has evolved to include direct patient care and interprofessional team models. Proper documentation of training and certification is required to verify eligibility for providing specialized services and for reimbursement.

Objectives: The objectives of this study were to assess pharmacists' views and perceptions on credentialing with respect to (1) familiarity and perceived importance of credentialing; (2) satisfaction with current credentialing tracking systems; and (3) challenges in adopting a centralized credentialing platform.

Methods: This study used a cross-sectional, survey design to examine pharmacist perceptions of credentialing. The survey, distributed by the American Pharmacists Association from November 18, 2017 to December 2, 2017, consisted of 11 demographic items and 22 items about familiarity, importance, satisfaction and current systems of credentialing in pharmacy practice. Descriptive statistics were used to characterize the sample and outcome variables. Content analysis was conducted on freeform responses.

Results: Data were analyzed from 446 (7.3\%) completed surveys of the 6,144 distributed. Respondents were primarily represented by pharmacists from chain stores (29.6\%), outpatient clinics (16.6\%), and academic settings (15.2\%). Job titles included staff pharmacist (33.9\%), clinical pharmacist (21.3\%), and manager positions (18.3\%). Nine of 10 pharmacists reported familiarity with credentialing and considered credentialing as important to the pharmacy profession. Majority agreed with the importance of having a centralized online platform to store credentialing information (96.1\%) and to obtain reimbursement (97.1\%). Poor integration of data among different platforms (16\%) was a common reason for dissatisfaction with current tracking systems. Most respondents (96.5\%) were willing to provide information necessary for credentialing; however, over half were concerned about security of the information.

Conclusions: This study was among the first to examine pharmacist perceptions of credentialing. Pharmacists in this study were familiar with and responsive to participating in credentialing process. They were also supportive of having a centralized credentialing system, but held reservations about security of information.
\end{abstract}

Keywords: Credentialing; Pharmacy; Pharmacist; Reimbursement; Board Certification; Pharmacy Licensure

\section{Background}

Pharmacist responsibilities have expanded beyond medication distribution to direct patient care services in healthcare systems. The pharmacist's role in a interprofessional healthcare team ranges from screening and providing vaccinations to performing medication therapy management (MTM) and practicing under collaborative practice agreements in diverse settings. ${ }^{1-3}$ With the diversification and specialization of pharmacists' roles, it has become increasingly important to gain appropriate training and certifications to serve in these specialized positions. ${ }^{4}$ Proper documentation of certification and ongoing training must be in place so that employers, thirdparty payers, and other stakeholders can access and verify the eligibility for providing specialized services within the pharmacy profession. ${ }^{4,5}$

Corresponding author: Anandi V. Law, BPharm, MS, PhD, FAPhA, Professor, Department of Pharmacy Practice and Administration and Associate Dean for Assessment, Western University of Health Sciences College of Pharmacy, Pomona, CA Email: alaw@westernu.edu
Credentialing is a process to verify the qualifications and practice history of healthcare professionals. ${ }^{6,7}$ Appropriate documentation of licensure status and certifications is commonly required by employers and third-party payers to establish employment and reimbursement of services. Demonstrating enhanced provider credentialing, beyond professional degree and licensure, is essential among all health professionals to bill for the provision of patient care services. ${ }^{8}$ The Centers for Medicare and Medicaid Services (CMS) requires physicians to disclose their licensing information, National Provider Identifier (NPI), specialties, practice location, and previous employment. ${ }^{9,10}$ This information is periodically updated and verified for accuracy when applying for billing privileges through CMS. ${ }^{9}$ Traditionally, pharmacists have not been able to bill third-party payers, including Medicare, for providing patient care services. ${ }^{11}$ Recently, some states have adopted legislation to expand the pharmacists' scope of practice by granting advanced practice pharmacist (APP) and/or clinical pharmacist practitioner (CPP) status. ${ }^{12-14}$

These developments in the profession have generated an increasing need for organizations to verify the qualifications that demonstrate a pharmacist's competency to deliver these 
services. ${ }^{14-17}$ In the pharmacy profession, required and/or recommended credentials range from entry-level credentials (i.e. academic degrees, licensure) to more advanced-level credentials (i.e. residency training, board certification) which demonstrate competence in providing complex and specialized professional services. ${ }^{4}$ Part of the credentialing process also involves documenting maintenance of professional competencies and engagement in continued professional development through continuing-education activities, certification renewal, or history of previous clinical work experience. ${ }^{18}$ Pharmacists practicing in interprofessional care models should be be familiar with the credentialing process. To the authors' knowledge, there are no studies examining pharmacists' awareness, perceptions, or willingness to participate in the credentialing process.

\section{Objective}

The objective of this study was to assess pharmacists' views and perceptions on credentialing with respect to (1) familiarity and perceived importance of credentialing; (2) satisfaction with current credentialing tracking systems; and (3) challenges in adopting a centralized credentialing platform.

\section{Methods}

The study used a cross-sectional, survey design to collect information from pharmacists regarding their perceptions of credentialing. This study received approval from the Western University of Health Sciences Institutional Review Board (\#X17/IRB/105). The sample of pharmacists was identified through the American Pharmacists Association (APhA) database, which included both members and non-members. ${ }^{19}$ An e-mail invite for voluntary participation in the survey was distributed by APhA with an open participation period of November 18, 2017 to December 2, 2017. The survey used an online Qualtrics platform and was linked in the email invitation distributed by APhA. ${ }^{19,20}$

A total of 33 questions was included in the survey (11 items about demographic information and 22 items about views and perceptions of credentialing in pharmacy practice). Questions regarding the views and perceptions of credentialing consisted of (1) familiarity with credentialing in pharmacy practice, (2) perceived importance of credentialing, (3) current ways to track credentialing information, (4) level of support for using a centralized credentialing system, (5) concerns related to a centralized credentialing system, and (6) willingness to provide personal and professional information to a centralized credentialing system. Survey responses were recorded on a four-point agreement scale. Freeform response options were available for respondents to elaborate on concerns regarding access and security of information and satisfaction with current credentialing systems.

Descriptive statistics were used to analyze responses from the survey questions using SPSS Version 28. Bivariate correlations were examined based on respondents' familiarity with and importance of credentialing. Dancey \& Reidy measure was used to interpret correlation coefficient to weak (0.1-0.3), moderate (0.4-0.6), strong (0.7-0.9), and perfect (1). ${ }^{21}$ Subgroup analyses were also conducted using chi-squared tests based on participants' willingness to provide information, board certification status, job titles, and participation in direct patient care. Content analysis was performed to categorize free-form responses. Responses were independently coded by three researchers (SL, ND, AVL), and the categories were consolidated to common themes.

\section{Results}

Respondent Characteristics

Of the 6,144 surveys emailed, 446 (7.3\%) were completed. As seen in Table 1, a majority of the respondents held an active pharmacist license (96.2\%). The average length (in years) of holding a pharmacist license was 17.4 years (median $=13$, standard deviation $[S D]=15.9)$. Respondents primarily represented pharmacists from chain pharmacies (29.6\%), outpatient clinics (16.6\%), and academia settings (15.2\%). Many respondents were in staff pharmacist (33.9\%), clinical pharmacist (21.3\%), and manager (18.3\%) positions. Responses were received from 43 states; with none from Delaware, Hawaii, Idaho, Montana, Nevada, New Hampshire, and Vermont. When respondents were grouped into five geographical regions (Midwest, Northeast, Southeast, West, and Southwest) of their primary licensure practice, there were no differences in survey responses from the different geographical regions. 
Table 1. Respondent Demographic Characteristics

\begin{tabular}{|c|c|}
\hline Category & Result \\
\hline Active Pharmacist License (\%) & $96.2 \%$ \\
\hline Gender, Female (\%) & $58.6 \%$ \\
\hline Length of Practicing as a Licensed Pharmacist (Years) & $17.4 \pm 15.9$ years \\
\hline \multicolumn{2}{|l|}{ Work Setting ${ }^{\dagger}$} \\
\hline Chain pharmacy & $29.6 \%$ \\
\hline Outpatient setting in health-system & $16.6 \%$ \\
\hline Academic setting & $15.2 \%$ \\
\hline Independent pharmacy & $12.6 \%$ \\
\hline Industry setting & $10.2 \%$ \\
\hline Inpatient setting in health-system & $9.9 \%$ \\
\hline \multicolumn{2}{|l|}{ Job Title† } \\
\hline Staff Pharmacist & $33.9 \%$ \\
\hline Clinical Pharmacist & $21.3 \%$ \\
\hline Manager & $18.3 \%$ \\
\hline Owner & $10.1 \%$ \\
\hline Director of Pharmacy & $4.5 \%$ \\
\hline Faculty & $8.1 \%$ \\
\hline Resident/Fellow & $6.1 \%$ \\
\hline Board Certification Statusł, Yes (\%) & $17.7 \%$ \\
\hline Providing Direct Patient Care, Yes (\%) & $76.4 \%$ \\
\hline \multicolumn{2}{|l|}{ Residential Area per Geographic Region (\%) } \\
\hline Midwest & $27.9 \%$ \\
\hline Northeast & $25.0 \%$ \\
\hline Southeast & $24.0 \%$ \\
\hline West & $16.7 \%$ \\
\hline Southwest & $6.4 \%$ \\
\hline
\end{tabular}

+ Participants were allowed to select more than one choice. Therefore, the percentages may exceed $100 \%$. ¥ More than half of the respondents (57.8\%) did not answer their board certification status. Unknown status was coded as no board certification.

Participants were asked to identify types of direct patient care services provided in their daily activities. Commonly recognized activities included comprehensive medication reviews, immunizations, and medication management (Figure 1). Respondents who provided patient care were more likely to agree that pharmacists should have to document their credentials for payment of services. There were no statistically significant differences in response patterns regarding familiarity with credentialing, importance of credentialing, importance of reimbursement for services, or willingness to provide credentialing information between respondents who provided patient care services and those who did not. Respondents who had board certification(s) were significantly more likely to be familiar with credentialing requirements, have a higher perceived importance of credentialing, and be more willing to provide credentialing information than respondents who did not have a board certification. 
Figure 1. Commonly provided direct patient care services by the respondents

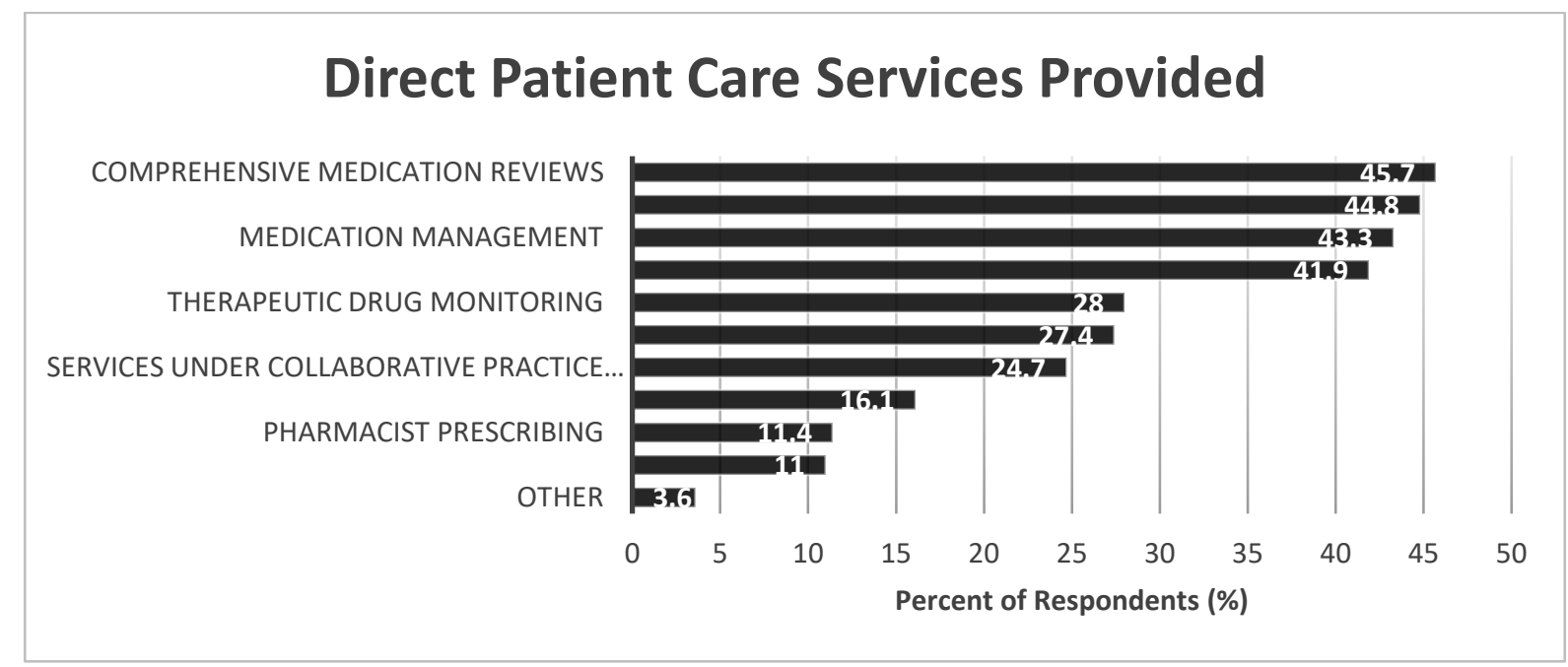

Multiple selections were allowed. Choices available other than the above shown include: blood pressure, compounding, drug diversion monitoring, drug information consultations, formulary management, genetic testing, long-term care consultation, medicine box program, medication reconciliation, medication therapy management services, prescribing birth control, smoking cessation

The Current View of Credentialing in the Pharmacy Profession A high percentage of the respondents (67.4\%) were familiar with credentialing requirements in healthcare. About $91.1 \%$ respondents reported that credentialing is somewhat to very important in the pharmacy profession. A majority of the respondents also indicated that it is somewhat to very important to have a centralized online platform to store credentialing information (94.7\%). Almost all (98.4\%) acknowledged the somewhat to very important to get reimbursed for providing direct patient care services. Similarly, about $90.9 \%$ of the respondents agreed that pharmacists should use a credentialing system to obtain reimbursement. (Table 2)

Table 2. Responses about the current view on credentialing in the pharmacy profession

\begin{tabular}{|c|c|c|c|c|c|}
\hline Survey Item & $\mathbf{N}$ & $\begin{array}{l}\text { Very } \\
(\%)\end{array}$ & $\begin{array}{c}\text { Somewhat } \\
(\%)\end{array}$ & $\begin{array}{l}\text { Not too } \\
(\%)\end{array}$ & $\begin{array}{l}\text { Not at } \\
\text { all (\%) }\end{array}$ \\
\hline $\begin{array}{l}\text { I am familiar with credentialing requirements in the } \\
\text { healthcare profession. }\end{array}$ & 365 & 24.4 & 43.0 & 23.3 & 9.3 \\
\hline Credentialing is important in the pharmacy profession. & 364 & 52.7 & 37.6 & 8.8 & 0.8 \\
\hline $\begin{array}{l}\text { I agree that pharmacists should use credentialing to } \\
\text { obtain reimbursement. }\end{array}$ & 352 & 47.4 & 43.5 & 5.7 & 3.4 \\
\hline $\begin{array}{l}\text { It is important to get reimbursed for providing patient } \\
\text { care services in the pharmacy profession. }\end{array}$ & 374 & 86.1 & 12.3 & 1.6 & 0 \\
\hline $\begin{array}{l}\text { I am willing to provide information needed for } \\
\text { credentialing to get reimbursed for patient care } \\
\text { services. }\end{array}$ & 359 & 79.7 & 16.7 & 1.9 & 1.7 \\
\hline $\begin{array}{l}\text { I am satisfied with the system that I (or my employer) } \\
\text { use to track information regarding my license status, } \\
\text { continuing education hours, training and certifications. }\end{array}$ & 354 & 52.5 & 43.2 & 3.4 & 0.8 \\
\hline $\begin{array}{l}\text { It is important to have a centralized location to store } \\
\text { credentialing information. }\end{array}$ & 352 & 68.8 & 25.9 & 4.5 & 0.9 \\
\hline $\begin{array}{l}\text { I am concerned about access and security of } \\
\text { credentialing information stored in a centralized } \\
\text { location. }\end{array}$ & 330 & 22.7 & 37.9 & 29.1 & 10.3 \\
\hline
\end{tabular}


Weak positive correlational relationships were observed between respondent familiarity with credentialing and the following factors: perceived importance $(r=0.21, p<0.05)$, willingness to provide information $(r=0.22, p<0.05)$, and support for mandating credentialing for reimbursement of services $(r=0.25, p<0.05)$.
Moderate positive correlations were observed between perceived importance of credentialing and the following factors: willingness to provide information $(r=0.54, p<0.05)$, the importance of having a centralized platform ( $r=0.31, p<0.05)$, and support for the use of a centralized platform $(r=0.42$, $\mathrm{p}<0.05$ ). (Table 3)

Table 3. Bivariate correlation between familiarity and importance of credentialing in the health care profession and other survey responses

\begin{tabular}{|l|c|}
\hline & $\mathrm{R}$ \\
\hline FAMILIAR with credentialing in the health care profession & \\
\hline IMPORTANT to have credentialing in the pharmacy profession & $0.21^{*}$ \\
\hline WILLING to provide information for credentialing & $0.22^{*}$ \\
\hline AGREE on mandating credentialing in pharmacy & $0.25^{*}$ \\
\hline IMPORTANT to have credentialing in the pharmacy profession & \\
\hline WILLING to provide information for credentialing & $0.54^{*}$ \\
\hline IMPORTANT to have a centralized credentialing platform & $0.31^{*}$ \\
\hline SUPPORT the use of a centralized credentialing platform & $0.42^{*}$ \\
\hline AGREE to mandating credentialing in pharmacy & $0.65^{*}$ \\
\hline$*$ p $<0.05$ &
\end{tabular}

Experience with Using Credential Tracking Systems

Respondents reported that their employers currently track the following information: licensure (94.7\%), sanctions (61.2\%), advanced training (59.2\%), and continuing education hours (50.7\%). About three-fourths of the respondents (74.7\%) reported using the Continuing Pharmacy Education Monitor (CPE Monitor) provided by the National Association of Board of Pharmacy (NABP) to track their credentialing information. Other platforms used included the Pharmacist's Letter (C) CE tracker $(28.3 \%)$, employer-based trackers $(10.3 \%)$, self-track using Microsoft Excel (8.5\%), and state-specific third-party platforms (6.5\%). ${ }^{22}$

Most of the respondents indicated they were satisfied (95.7\%) with the way that credentialing information was being tracked. Of the 446 participants completed the survey, 285 participants provided thoughtful input to a free-response question asking reasons for satisfaction and dissatisfaction with the credentialing tracking system. The response to the freeresponse question was used to perform content analysis (Appendix - The original survey questions $15 \& 25$ ). Two independent researchers coded the theme based on the response. Common theme coded for question 15 regarding satisfaction and/or dissatisfaction with the current system includes: ease of use, comprehensiveness, all in different system, accuracy of information, lack of notification, difficult to use, lack of timeliness, etc.

The most common reasons for satisfaction with the credentialing tracking systems included comprehensiveness (23.3\%), ease of use (22.0\%), and accuracy (7.9\%). Common reasons for dissatisfaction with credentialing tracking systems include poor integration of data among the different platforms (16.0\%), difficulty of use (13.4\%), and lack of notification for renewal notification for each license and certification (8.7\%). 


\title{
CREDENTIALING INFORMATION
}

\author{
Information Contained in Credentialing Platform \\ Information of Concern for Access \& Security \\ ه Information Tracked by Employers
}

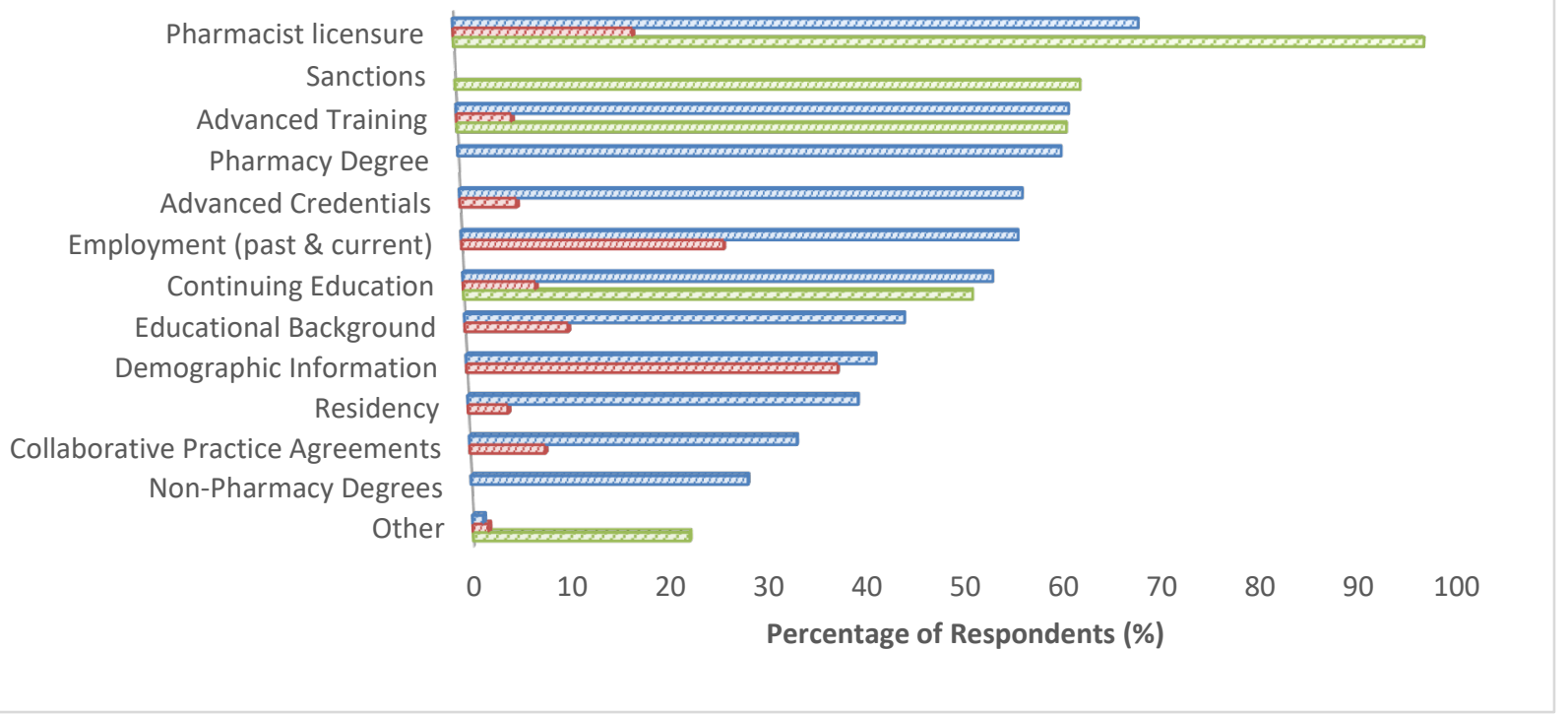

Other (information tracked by employer): board certifications, CPR certification, drug testing results, and liability insurance. Other (Information of concern for access \& security): Board of Pharmacy actions - even if dismissed, Personal Information (home \& work address) published publicly, social security number Other (Information contained in credentialing platform): Attending training without C.E. attached, board certification, certifications, CPR, drug testing, HIV Certification, immunization training, interventions

\section{Centralized Platform for Credentialing}

A high proportion of the respondents $(68.8 \%)$ reported that it is important to have a central location to store credentialing information. Almost all (96.5\%) were willing to provide the information needed for credentialing. However, over half of the respondents were concerned about access and security of professional information used for credentialing. The most common concerns included potential breach of private personal information (28.7\%), identity theft (18.9\%), and a single entity having control over personal and/or professional information (18.0\%).

\section{Discussion}

This study was among the first to examine practitioner views and perceptions of credentialing within the profession. Credentialing is gaining importance as pharmacists are increasingly engaged in direct patient care from administering immunizations and MTM at a community pharmacy to providing comprehensive medication management in institutional settings. ${ }^{16,23,24}$ In addition, scope of practice has been expanded in several states for pharmacists with eligible training and certification. ${ }^{5,18-21}$ Board certification has become increasingly important in the pharmacy profession as a way to ensure the direct patient care service is being provided by a qualified pharmacist. $^{5}$ Currently, a standard process of credentialing is lacking for the pharmacy profession. The frequency and method of verifying eligibility happens at an employer's discretion, which may lead to a wide range of discrepancy within the health care system. A uniform process of verifying and documenting eligibility to ensure standardization of competencies and quality of the pharmacists with a variety of specialty areas may help fuel the advancement of the pharmacy practice.

The authors expected that pharmacists who are involved with direct patient care would be more familiar with credentialing; however, the results did not support this hypothesis. A majority of the licensed pharmacists who responded to the survey regarded credentialing as important to the pharmacy profession and should be used in order to receive 
reimbursement for direct patient care services. Many of the respondents were aware that licensure, sanctions, and/or certifications were being tracked by their employers periodically. A similar proportion also indicated the need for having a centralized information technology (IT) platform to store credentialing information. Based on the responses, there could be a significant uptake of the centralized credentialing platform if the system were both secure and automated.

A majority of the respondents had reservations related to the accessibility of their information by unknown entities and individuals. In spite of the security concerns, most respondents expressed a willingness to provide personal and professional information to the centralized credentialing platform. The perceived benefits of keeping a record of credentialing information in a central platform approved by a regulatory body may outweigh the risk of electronic platforms being compromised. Employers, third-party payers, and other credentialing bodies may need to carefully consider the minimum information required for credentialing to address pharmacists' concerns and promote the credentialing process.

All respondents reported using various platforms to track credentialing information, and some were not satisfied with the tracking systems for credentialing information. Reasons for dissatisfaction with these tracking systems included a lack of integration between platforms, difficulty in use, and a lack of notifications for the renewal status. One disadvantage of the commonly used platform provided by the National Association of Boards of Pharmacy (NABP) called continuing pharmacy education (CPE) Monitor ${ }^{28}$ is that it only tracks continuing education credits accredited by the Accreditation Council for Pharmacy Education, but not others. Respondents identified that it was inconvenient to manually track other credentials using a separate platform. Additionally, the NABP CPE monitor@ does not indicate which continuing education credits apply to each license and/or certification. Some pharmacists hold licenses in multiple states and/or certifications to provide services across the nation, and it may take a significant amount of time for the practicing pharmacists to keep track of the information needed during the renewal period. ${ }^{29-33}$ A credentialing platform that integrates data from multiple sources might be useful for facilitating the license and certification of the renewal process. In the current state of a value-based healthcare system, the quality of care and provider quality are being continually evaluated. As pharmacists pursue national provider status, it is important to demonstrate competency through appropriate documentation of licensure and certification. Having a centralized platform to document professional qualifications and practice history may positively contribute to the advancement of the profession similar to platforms used by other healthcare professionals ${ }^{34}$ to justify billing and reimbursement of patient care services. The results from this study demonstrate the market need and demand for an integrated credentialing system; as well aspractitioner willingness and interest in adopting such a system.

Respondents to the survey appeared to be representative of the national sample, but there was no analysis conducted of possible nonresponse bias. ${ }^{35}$ The low response rate of seven percent may hinder extrapolation of results to the general population. The positively skewed data may be indicative of self-selection bias as those who provided their emails to the organization and those who responded may also be more engaged with the pharmacy professional society, specifically American Pharmacist Association. Additionally, participants who are familiar with and have positive views about credentialing may have been more responsive to complete the survey. A future study may focus on assessing the needs of the centralized credentialing platform from other professional societies' list serves, employer-based survey distribution routes, and forwarding paper mail using publicly available license information in each state. In addition, perceptions of and challenges to credentialing need to be examined from the perspective of employers and payers.

\section{Conclusion}

The results of this study showed that pharmacists are familiar with and value the credentialing process in pharmacy profession. The study also revealed that pharmacists are responsive to participating in the credentialing process. Respondents were supportive of having a centralized credentialing system, but held reservations about security of information. Future studies examining the need for a centralized credentialing platform from employer and thirdparty payer perspectives would provide a comprehensive picture of the current status and future challenges for credentialing in the pharmacy profession.

Acknowledgements: The authors would like to thank American Pharmacist Association for distributing the survey and Ralphs Pharmacy for their support of this project.

Funding: This project was awarded with a travel grant of $\$ 1,000$ by the APhA.

Conflicts of Interest: The study was initiated by the American Pharmacists Association.

Treatment of Human Subject: This study received approval from the Western University of Health Sciences Institutional Review Board (\#X17/IRB/105). 


\section{References}

1. Hirsch JD, Steers N, Adler DS, et al. Primary carebased, pharmacist-physician collaborative medication-therapy management of hypertension: A randomized, pragmatic trial. Clin Ther. 2014. doi:10.1016/j.clinthera.2014.06.030

2. Hwang AY, Gums TH, Gums JG, Uni- HP. The benefits of physician- pharmacist collaboration. J Fam prcatice. 2017. doi:10.1115/ICEF2017-3584

3. Nicole P, Rouse MJ. Scope of contemporary pharmacy practice: Roles, responsibilities, and functions of pharmacists and pharmacy technicians Executive summary. Am J Heal Pharm. 2010. doi:10.2146/ajhp100057

4. Burns AL. Credentialing and privileging of pharmacists: A resource paper from the Council on Credentialing in Pharmacy. Consult Pharm. 2014. doi:10.2146/ajhp140420

5. Saseen JJ, Grady SE, Hansen LB, et al. Future clinical pharmacy practitioners should be board-certified specialists. Pharmacotherapy. 2006. doi:10.1592/phco.26.12.1816

6. IOM I of medicine. Medicare: A Strategy for Quality Assurance.; 1990. doi:10.1097/00001786199107000-00013

7. The Joint Commission. Sentinel Event Alert Issue 26 : Delays in treatment. Jt Comm Sentin Event Alert. 2002.

8. Summit I of M (US) C on the HPE, Greiner AC, Knebel E. Health Professions Education: A Bridge to Quality. National Academies Press (US); 2003. doi:10.17226/10681

9. Overview. 2018. https://www.cms.gov/Regulationsand-Guidance/AdministrativeSimplification/NationalProvldentStand/. Accessed July 26, 2019.

10. The New National Provider Identifier. J Oncol Pract. 2006;2(6):281. doi:10.1200/JOP.2006.2.6.281

11. Kliethermes MA. Understanding health care billing basics. Pharm Today. 2017. doi:10.1016/j.ptdy.2017.06.041

12. National Governors Association. The Expanding Role of Pharmacists in a Transformed Health Care System. https://classic.nga.org/cms/home/nga-center-forbest-practices/center-publications/page-healthpublications/col2-content/main-content-list/theexpanding-role-of-pharmacist.html. Published 2015. Accessed August 1, 2019.

13. Knoer SJ, Eck AR, Lucas AJ. A review of American pharmacy: education, training, technology, and practice. J Pharm Heal care Sci. 2016;2:32. doi:10.1186/s40780-016-0066-3
14. Woolf R, Locke A, Potts C. Pharmacist prescribing within an integrated health system in Washington. Am J Heal Pharm. 2016;73(18):1416-1624. doi:10.2146/ajhp150846

15. Consortium recommendations for advancing pharmacists' patient care services and collaborative practice agreements. J Am Pharm Assoc. 2013. doi:10.1331/JAPhA.2013.12211

16. Ourth H, Groppi J, Morreale AP, Quicci-Roberts K. Clinical pharmacist prescribing activities in the Veterans Health Administration. Am J Heal Pharm. 2016. doi:10.2146/ajhp150778

17. Federal Motor Carrier Safety Administration, (FMCSA), DOT. Process for Department of Veterans Affairs (VA) Physicians To Be Added to the National Registry of Certified Medical Examiners. Final rule. Fed Regist. 2018;83(112):26846-26884.

http://www.ncbi.nlm.nih.gov/pubmed/30019876. Accessed October 24, 2018.

18. Credentialing and privileging of pharmacists: $A$ resource paper from the Council on Credentialing in Pharmacy. Am J Heal Pharm. 2014;71(21):18911900. doi:10.2146/ajhp140420

19. Home | American Pharmacists Association. https://www.pharmacist.com/. Accessed October 24, 2018.

20. The Leading Research \&amp; Experience Software Qualtrics. https://www.qualtrics.com/. Accessed October 24, 2018.

21. Akoglu H. User's guide to correlation coefficients. Turkish J Emerg Med. 2018;18(3):91-93. doi:10.1016/j.tjem.2018.08.001

22. Therapeutic Research Center. Pharmacist's Letter. Therapeutic Research Center. https://pharmacist.therapeuticresearch.com/CE/AllCourses. Published 2018. Accessed December 5, 2018.

23. Dugan BDA. Enhancing community pharmacy through advanced pharmacy practice experiences. Am J Pharm Educ. 2006. doi:10.5688/aj700121

24. Haddad AMR, Coover KL, Begley KJ, Tilleman JA. An advanced pharmacy practice experience in community engagement. Am J Pharm Educ. 2012. doi:10.5688/aj7205125

25. Williams CR, Woodall T, Wilson CG, et al. Physician perceptions of integrating advanced practice pharmacists into practice. J Am Pharm Assoc. 2018;58(1):73-78.e2. doi:10.1016/J.JAPH.2017.10.014

26. NCBOP: Clinical Pharmacist Practitioners. http://www.ncbop.org/pharmacists_cpp.htm. Accessed December 5, 2018. 
27. California State Board of Pharmacy. California State Board of Pharmacy. State of California .

https://www.pharmacy.ca.gov/applicants/app.shtml . Published 2016. Accessed December 5, 2018.

28. CPE Monitor Service | National Association of State Boards of Pharmacy. https://nabp.pharmacy/cpemonitor-service/. Accessed October 24, 2018.

29. Fortney JC, Pyne JM, Mouden SB, et al. Practicebased versus telemedicine-based collaborative care for depression in rural federally qualified health centers: A pragmatic randomized comparative effectiveness trial. Am J Psychiatry. 2013. doi:10.1176/appi.ajp.2012.12050696

30. Zullig LL, Melnyk SD, Stechuchak KM, et al. The Cardiovascular Intervention Improvement Telemedicine Study (CITIES): Rationale for a Tailored Behavioral and Educational PharmacistAdministered Intervention for Achieving Cardiovascular Disease Risk Reduction. Telemed eHealth. 2014. doi:10.1089/tmj.2013.0145

31. Niznik JD, He H, Kane-Gill SL. Impact of clinical pharmacist services delivered via telemedicine in the outpatient or ambulatory care setting: A systematic review. Res Soc Adm Pharm. 2018.

doi:10.1016/j.sapharm.2017.10.011
32. Zillich AJ, Snyder ME, Frail CK, et al. A randomized, controlled pragmatic trial of telephonic medication therapy management to reduce hospitalization in home health patients. Health Serv Res. 2014. doi:10.1111/1475-6773.12176

33. Wellman BR, Frail CK, Zillich AJ, Snyder ME. Pharmacists' Experiences with a Telephonic Medication Therapy Management Program for Home Health Care Patients. Consult Pharm. 2015. doi:10.4140/TCP.n.2015.163

34. Ramirez E, Schumann L, Agan D, et al. Beyond competencies. J Am Assoc Nurse Pract. 2018;30(10):570-578. doi:10.1097/JXX.0000000000000139

35. Pharmacists : Occupational Outlook Handbook: : U.S. Bureau of Labor Statistics. Bureau of Labor Statistics. https://www.bls.gov/ooh/healthcare/pharmacists.ht m\#tab-3. Accessed August 27, 2019. 